\title{
LA PUERTA COMO DOGMA: A PROPÓSITO DE UN NUEVO DESCUBRIMIENTO DE LA IGLESIA ROMÁNICA DE SAN ZOILO DE CARRIÓN DE LOS CONDES (PALENCIA)
}

\author{
POR \\ José Luis Senra Gabriel y Galán \\ Universidad de Santiago de Compostela
}

En los últimos quince años el que fuera monasterio de San Zoilo de Carrión de los Condes (Palencia) ha sorprendido a los especialistas en Historia del Arte con importantes hallazgos pertenecientes a su materialización románica. Desde su portada occidental a su compleja torre noroeste de fachada pasando por diferentes piezas descontextualizadas, todo ello ha contribuido a valorar uno de los conjuntos monumentales de más importancia gestionados por la abadía de Cluny en la Península Ibérica. En los últimos meses se ha descubierto una de las puertas de acceso a su desaparecida tribuna occidental sobre la que se trata en este artículo.

Palabras claves: Románico; San Zoilo; Carrión de los Condes; Cluny; Monasterio; Puerta occidental.

Over the past fifteen years art historians have been surprised by the significant Romanesque findings at the site of the former monastery of San Zoilo in Carrión de los Condes (Palencia). From its western doorway and complex northwestern facade tower to an assortment of decontextualized pieces, all of these findings have contributed toward the evaluation of one of the most important monumental groups of the Cluniac Order in the Iberian Peninsula. Among the most recent discoveries is the doorway to the lost western tribune, the subject of this article.

Key words: Romanesque; San Zoilo: Carrión de los Condes; Cluny; Monastery; Western doorway.

Desde hace ya más de una década, los restos del que fuera priorato de Cluny entre 1076 y 1435, el monasterio de San Zoilo de Carrión de los Condes (Palencia), fundamentalmente los correspondientes a su desaparecida iglesia románica, se han incrementado notablemente ${ }^{1}$. La re-

1 José Luis Senra Gabriel y Galán, "La portada occidental recientemente descubierta en el monasterio de San Zoilo de Carrión de los Condes", Archivo Español de Arte, LXVII (1994), pp. 57-72; "Nuevos hallazgos románicos en 
ciente restauración de la torre noroeste, de época románica en sus dos terceras partes y con un recrecimiento de época moderna realizado en ladrillo, ha traído consigo un nuevo hallazgo. Aunque la parte románica ya había sido objeto de una limpieza años atrás en la que se descubrieron dos tramos de escaleras, ahora se ha procedido a liberar el acceso original que se abría a la nave del Evangelio de la iglesia. Esta puerta había sido literalmente emparedada durante la construcción de la nueva iglesia barroca por la disposición en la misma esquina en que se encuentra, de un potente machón (figs. 1-3). Hay que recordar que la actual construcción del siglo XVII procedió a reaprovechar casi en su integridad el perímetro mural del templo románico derribándose tan sólo la cabecera. Esto concede al conjunto de San Zoilo un potencial arqueológico de primer orden ya que, además, al planificarse el edificio con nave única y elevarse la cota del piso, no debieron arrasarse los fundamentos de los pilares que separaban las tres naves románicas.

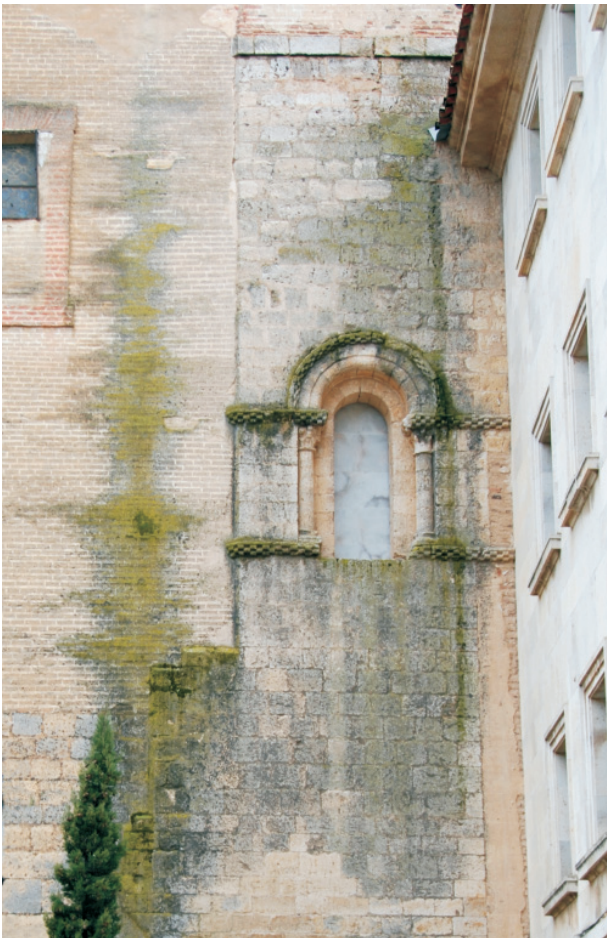

Fig. 1. Torre noroeste desde el flanco septentrional. San Zoilo de Carrión de los Condes (Foto: autor).

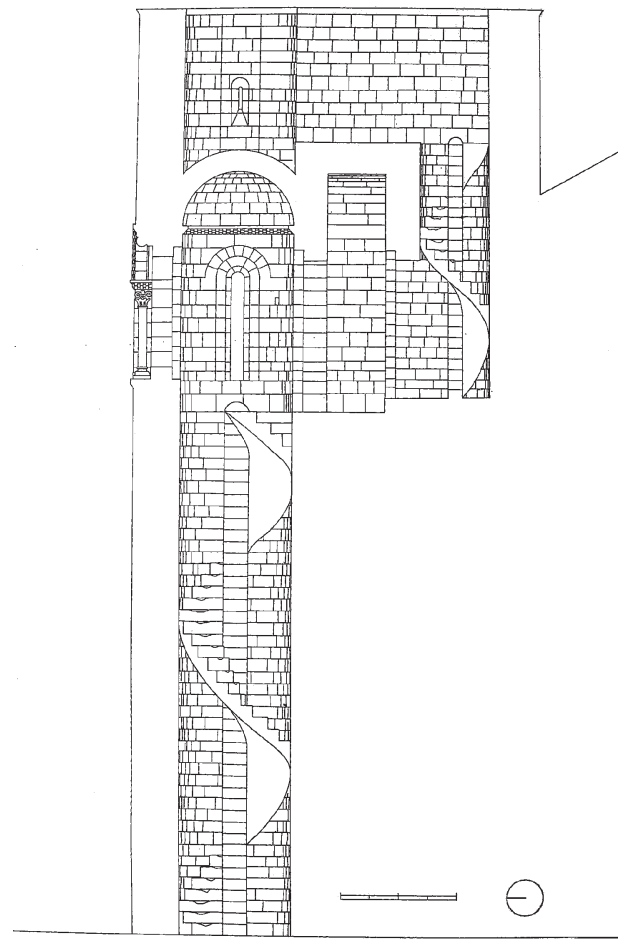

Fig. 2. Corte transversal (Norte-Sur) de la torre noroeste. San Zoilo de Carrión de los Condes (Dibujo: autor).

el monasterio de San Zoilo de Carrión de los Condes (Palencia)", Archivo Español de Arte, LXXIV (2001), pp. 88-95. A estos hallazgos hay que sumar los referidos al campo de la música y al área del arte textil: IsMAEL FernáNDEZ DE LA Cuesta, "Un tiento de Peraza entre papeles de San Zoilo de Carrión", Anuario Musical, 56 (2001), pp. 33-45; José LuIS Senra Gabriel y Galán, "Dos telas islámicas encontradas en el monasterio de San Zoilo de Carrión de los Condes", Goya 303 (2004), pp. 332-340. 


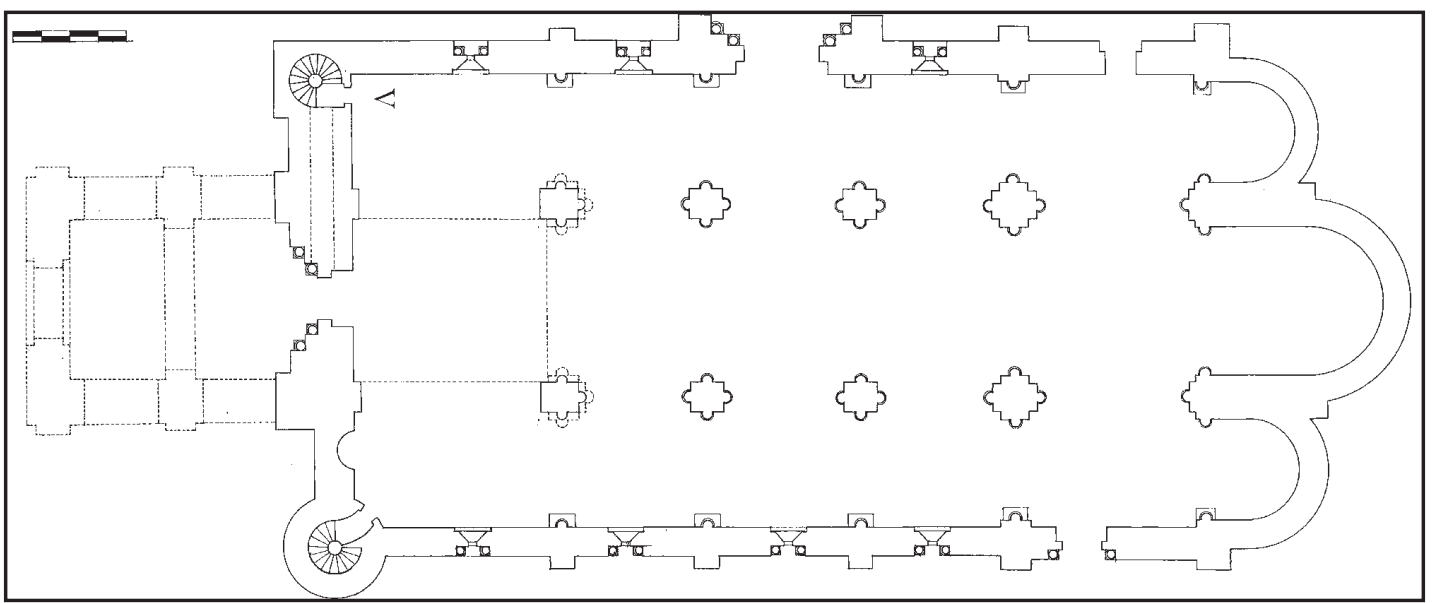

Fig. 3. Planta hipotética de la iglesia románica. San Zoilo de Carrión de los Condes. "V": Posición de la puerta aparecida en la torre noroeste (Foto: autor).

La puerta que ahora ha aparecido es un pequeño vano con la particularidad de incluir un reducido tímpano con un crismón ornamentado mediante motivos vegetales en sus laterales (fig. 4). La más inmediata conexión de esta tipología de puerta se encuentra en la vecina iglesia de San Martín de Frómista cuyo acceso a una de las torres de ángulo de la fachada, también la norte, se dispone de igual manera y con el crismón como elemento iconográfico único (fig. 5)2. Las conexiones de la iglesia de Frómista con la de Carrión han sido objeto de diferentes trabajos con objeto a profundizar en su respectiva realidad material románica tratando de minimizar, en la medida de lo posible, los dos importantes condicionantes que tienen cada una de ellas. En el caso de Frómista una restauración abusiva llevada a cabo entre 1894 y $1904^{3}$. El caso de Carrión, lo acabamos de reseñar, la supervivencia de muchos de sus elementos entre la estructura barroca que se superpuso sobre ella. Hace ya dos años, en el otoño de 2004, que en el área contigua al exterior de la fachada de San Zoilo se efectuó una excavación arqueológica en el curso de la cual aparecieron los restos de una estructura occidental cuya existencia se intuía a partir de los vestigios que quedan en el propio frontis de la iglesia y por la memoria documental del monasterio (fig. 3). A ello se sumaba el extraordinario estado de conservación de la portada de acceso al templo, impensable de no haberse mantenido a cubierto desde que fuera realizada. La utilización del término galilea para referirse a esta parte occidental del edificio es coherente con el contenido litúrgico de un templo que fue diseñado para adecuarse a los exigentes cánones cluniacenses. De raíz carolingia, esta zona occidental cobraba una especial vitalidad en los oficios de Pascua y en ella se desarrollaba una liturgia conmemorativa centrada en el misterio de

\footnotetext{
${ }^{2}$ A San Zoilo y Frómista habría que añadir la iglesia de San Isidoro de Dueñas si bien ésta, muy alterada en época moderna, si tuvo algún crismón no lo ha conservado. Otro referente para las tres es la iglesia del monasterio de SaintPé-de-Bigorre (Hautes-Pyrénées) en función de su fachada con torres cilíndricas y un bloque occidental. Sobre esta iglesia: ÉLIE LAmBert, "L'ancienne église de Saint-Pé de Bigorre", Al-Andalus, 8 (1943), pp. 189-209. Con algunas modificaciones en: Études Médiévales. Tome II: Le sud-ouest français, Paris, 1956, pp. 109-131. También: José LuIS SENRA, "La realidad material de la iglesia de San Martín de Frómista en el siglo XII", en: San Martín de Frómista ¿paradigma o historicismo?, Santander, 2005, pp. 55-57, n. 65.

${ }^{3}$ Sobre este asunto ver recientemente: Frómista 1066-1904. San Martín, centenario de una restauración (Exposición conmemorativa de la restauración de San Martín de Frómista, 1895-1904. Iglesia de San Martín de Frómista, julio a septiembre de 2004) (J. Rivera BLANCO, coord.), Santander, 2004.
} 
Fig. 4. Puerta de la torre noroeste desde la iglesia. San Zoilo de Carrión de los Condes (Foto: autor).
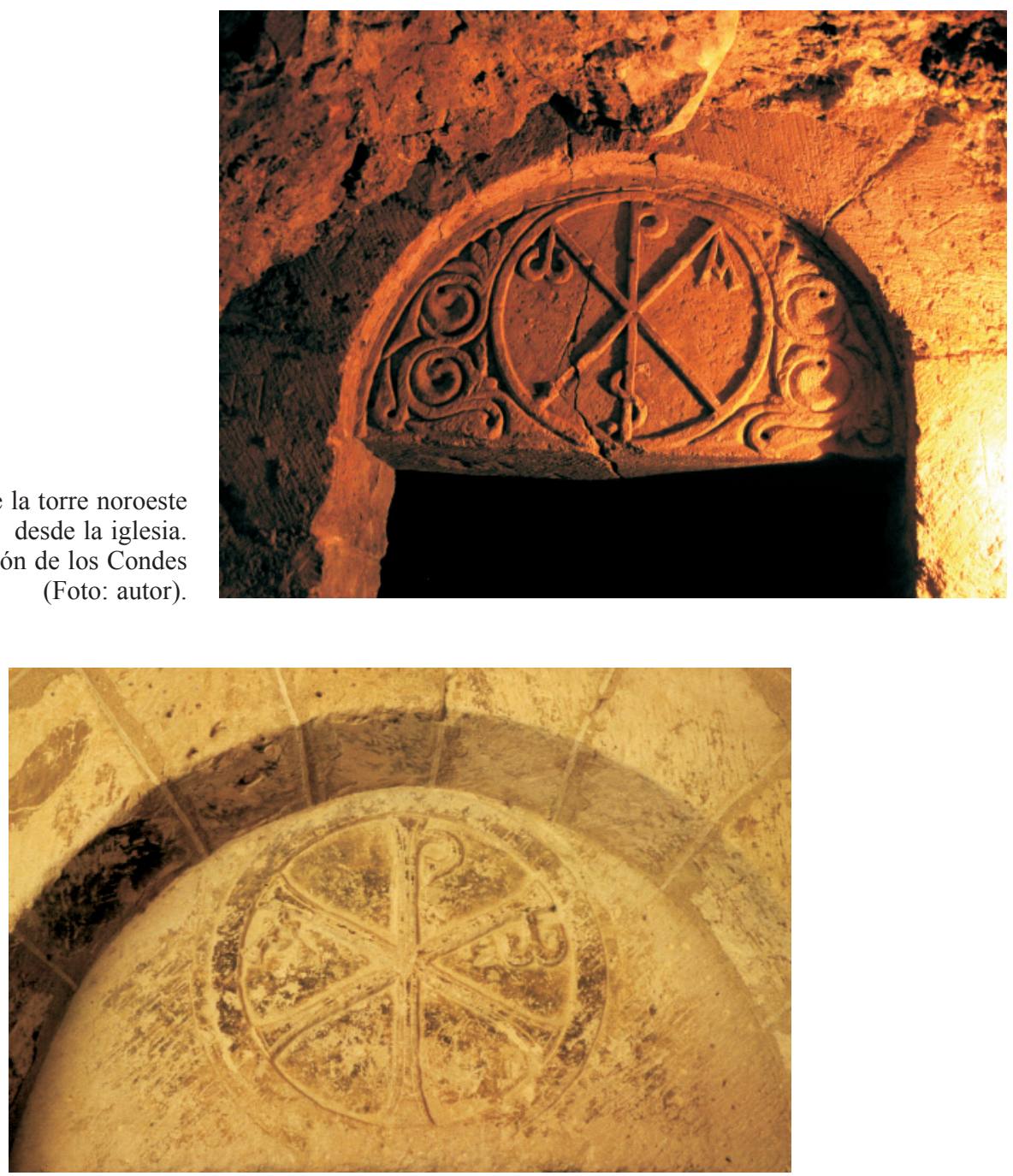

Fig. 5. Puerta de la torre noroeste desde la iglesia. San Martín de Frómista (Foto: autor).

la resurrección ${ }^{4}$. Esta verdadera metáfora arquitectónica del triunfo sobre la muerte se articulaba mediante dos torres laterales que posibilitaban, a través de dos segmentos de pasillo dispuestos en el espesor del muro de fachada, el acceso al piso alto del pórtico, con un pequeño ábside o bien abierto en forma de tribuna a la nave central ${ }^{5}$. Es decir constituían un espacio de tránsito para la procesión de monjes en su trayecto hacia el santuario alto en el que se realizaba una parada y un oficio específico sobre el altar que allí había. El acceso se llevaba a cabo por una

${ }^{4}$ CARol Heitz, Recherches sur les rapports entre Architecture et Liturgie à la époque carolingienne, París, 1963, pp. 120 y ss.; "Architecture et liturgie processionnelle à l'époque préromane" Revue de l'Art, 24 (1974), pp. 30-47.

${ }^{5}$ El tramo de pasillo noroeste queda prácticamente en su integridad mientras que del suroeste únicamente se aprecian vestigios. Ver: José LuIs SEnRA, "La realidad material de la iglesia de San Martín de Frómista en el siglo XII", pp. 45-47, fig. 7 . 
de las torres y, tras desarrollar el oficio, regresaban a las naves de la iglesia descendiendo por la otra ${ }^{6}$. Además en su zona inferior esta estructura daba cobijo a las sepulturas de una de las familias más próximas a la monarquía castellano-leonesa, la Banu-Gómez ${ }^{7}$.

En diferentes trabajos han sido perfiladas las conexiones con Frómista a partir de una tipología arquitectónica y escultórica muy semejante ${ }^{8}$. En una aportación reciente expuse las razones por las que resulta extraordinariamente difícil mantener que la iglesia románica de Frómista responde a mediados del siglo XI como todavía defienden algunos autores a partir de la hipótesis tradicional que la vinculaba al documento de 1066 por el que la reina Mayor, viuda de Sancho III de Navarra, dictaba testamento haciendo referencia a la edificación del monasterio ${ }^{9}$. Para ello me remitía a argumentos ya sostenidos por la mayor parte de los especialistas incidiendo además en aspectos apenas explorados como la madurez arquitectónica del edificio subrayando la semejanza de la fachada occidental con la de Carrión y la proximidad estilística de alguno de los capiteles de ambos conjuntos. La existencia de un pequeño pórtico occidental en la iglesia de San Martín, del que hasta la restauración quedaban los arcos de arranque en la fachada occidental de la iglesia que el arquitecto-restaurador eliminó, parece una probabilidad cada vez más evidente ${ }^{10}$. A esta tipología se añade la iglesia de San Isidoro de Dueñas, al igual que San Zoilo, también priorato de Cluny desde 1073. Estas semejanzas parecen poco compatibles con una cronología tan prematura como la de 1066 en la que la presencia cluniacense era apenas perceptible en el noroeste peninsular ${ }^{11}$. Posteriormente y a partir de un análisis estilístico, compositivo e iconográfico de sus capiteles he defendido la hipótesis de que la iglesia de Frómista fue una construcción realizada bajo el patronazgo de Cluny hacia 1118-112012. En 1118 la reina Urraca hizo entrega del monasterio de San Martín a la abadía borgoñona a través del prior Esteban de Carrión, a cuya administración última quedó sujeto el que hasta esa fecha fuera de propiedad real ${ }^{13}$. Una iconografía admonitoria de guerra y paz insistente además en la penalización de los vicios de los burgueses a través de capiteles y la intensa figuración aplicada a las cornisas, la mayor parte me-

${ }^{6}$ Es difícil de aseverar sin embargo, a partir de que en Frómista sólo existe el crismón en el acceso a la torre del lado del Evangelio, es decir la septentrional, no debe descartarse que este fuera un indicio de que aquella puerta fuera la del ascenso mientras que la meridional sirviera para el descenso. En torno a las galileas en Borgoña: KRISTINA KRÜGER, Die romanischen Westbauten in Burgund und Cluny. Untersuchungen zur Funktion einer Bauform, Berlin, 2003.

7 Sobre esta familia: José Luis Senra, "Mio Cid es de Bivar e nos de los condes de Carrión. Los Banu-Gómez de Carrión a la luz de sus epitafios”, Quintana, 5 (2006), pp. 233-267.

8 José Luis SEnRA, "Los programas constructivos de los monasterios benedictinos en el Camino de Santiago: arquitectura y ornamentación”, en: Monasterios y peregrinaciones en la España Medieval (Aguilar de Campoo, 2-5 agosto 2004), Santander, 2004, pp. 101-126.

9 Los argumentos más reiterados para seguir considerando la temprana fecha de 1066, se fundamentaron en asociar la referencia a las obras del monasterio con las dependencias claustrales y no necesariamente con la iglesia o bien que la construcción se dilató en el tiempo hasta fines del siglo XI. Sobre esta cuestión: José LuIS SENRA, "La realidad material de la iglesia de San Martín de Frómista en el siglo XII", pp. 39-42.

10 Estos vestigios debían ser similares a los que aún pueden verse en la fachada de San Zoilo. Sobre este asunto: José LuIs SENRA, “Aproximación a los espacios litúrgico-funerarios en Castilla y León: pórticos y galileas”, Gesta XXXVI/2 (1997), pp. 122-144.

11 José Luis SenRA, "La realidad material de la iglesia de San Martín de Frómista en el siglo XII”, en: San Martín de Frómista ¿paradigma o historicismo?, pp. 37 y ss.

12 José Luis SenRA, "De Castilla a Urgell: el retiro de Pedro Ansúrez, magnate de la corte de Alfonso VI. Algunas reconsideraciones sobre la escultura de su tiempo", en: La sculpture en Catalogne au XII siècle, un art au cœur de l'Europe, École Nationale des Chartes. París [en prensa]. Esta hipótesis había sido sugerida a lo largo del siglo XX por otros autores, entre los últimos cabría destacar a MARCEL DURLIAT ("Les origines de la sculpture romane à Jaca", Académie des Inscriptions et Belles-Lettres, 1978, p. 399; La sculpture romane de la route de Saint-Jacques, Mont-deMarsan, 1990, p. 282-297).

13 Julio A. Pérez Celada, Documentación del monasterio de San Zoilo de Carrión (1047-1300), Valladolid, 1986, doc. 21 , pp. 37-39. 
diante una profusa alternancia de rostros animales y humanos, encuentra un clima propicio a fines de la segunda década del siglo XII con el sonoro eco de las confrontaciones urbanas ${ }^{14}$. De tal manera que no resulta en absoluto extraño que la iglesia románica de Frómista siga los parámetros arquitectónicos de la institución a la que acabó subordinada: el priorato de San Zoilo. Y las evidencias que vamos acumulando apuntan cada vez con mayor solidez a que esta última iglesia estaba en marcha en el entorno de 1100 con un proceso constructivo verdaderamente rápido ${ }^{15}$. Los paralelos de marcas de cantería entre los templos de San Martín y San Zoilo, la articulación de los muros, los perfiles de ventanas, el hecho de que ambas tenían sus tres naves cubiertas con bóvedas de cañón, son demasiados elementos comunes para no considerar un hermanamiento de proyectos arquitectónicos a partir de la subordinación institucional de una a otra ${ }^{16}$. En definitiva, las convergencias entre los templos de estas tres instituciones -Dueñas, San Zoilo y Frómista-, parecen apuntar a la subordinación a un plan sujeto a unas directrices específicas codificadas por los cluniacenses en su área de colonización meridional.

Como vamos a ver, la puerta ahora descubierta presenta un crismón de tipología singular ${ }^{17}$. Es de sobra conocido que el crismón es el monograma de Cristo ( $\chi \rho \imath \sigma \tau ం \varsigma)$ formado por las dos primeras letras de su nombre el griego, $\chi$ (ji) y $\rho$ (rho), injertadas en una trama circular a las que se añade la $S: X P i$ tus $^{18}$. Recientes estudios han profundizado en el sincretismo o polivalencia del contenido del crismón corrigiendo algunos errores interpretativos. A partir de una dualidad de caracteres griegos y latinos además del nombre de Cristo permitiría leer uno de los términos a él asociados, PAX. Un término que alude a la proclama de san Pablo en torno a la reconciliación entre Dios y la humanidad a través del sacrificio de Cristo en la Cruz (Col. 1, 20). Su presencia asociada al crismón se puede rastrear ya en la miniatura del siglo $\mathrm{X}^{19}$.

Pero además las tres letras tendrían un significado alternativo ya que evocarían asimismo el misterio de la Trinidad: $P$ sería el Padre, $A$ el hijo y la $X$ el espíritu Santo ${ }^{20}$. Idéntica correspon-

${ }^{14}$ La llamada escultura marginal de los templos alcanza en el siglo XII una madurez que comparte Frómista en cuyas cornisas se reúne, con representativo acopio de lo primario y lo grotesco, el desorden que reina en el exterior del templo. Más aún en un clima como el reinante tras lo más encarnizado y visceral de los desórdenes urbanos surgidos tras 1109. Sobre la escultura de los aleros: Horst BredeKAMP, "Wallfahrt als Versuchung. San Martín de Frómista", en: Kunstgeschichte - aber wie? (C. FrUH / R. RosenBERG / H.-P. Rosinski, ed.), Múnich, 1989, pp. 221-258. En un contexto más amplio: NuRITH KenAAN-Kedar, Marginal Sculpture in Medieval France. Towards the Deciphering of an Enigmatic Pictorial Language, Aldershot, 1995, pp. 14-46.

${ }^{15}$ La lectura de los muros, visibles hasta el volteo de las bóvedas en su parte interior y desde una longitud que va desde el arranque de la cabecera hasta el hastial occidental permiten ver una clara determinación constructiva en la que no aparece sutura o quiebro alguno.

${ }^{16}$ Fuera de la catedral de Santiago de Compostela, ninguna de las iglesias románicas pertenecientes a grandes instituciones religiosas de las que tenemos restos, de las últimas décadas del siglo XI, planificaron una tectónica tan inequívocamente madura como la iglesia de San Martín de Frómista cuyos parámetros son fácilmente identificables en los restos de San Zoilo de Carrión de los Condes.

${ }^{17}$ Para la consulta de las diferentes tipologías de crismón resulta de gran utilidad la página web: http://www. claustro.com

${ }_{18}$ Recientes interpretaciones sobre la significación del crismón han corregido la extendida creencia de que la $S$ aludía al Espíritu Santo: Calvin B. Kendall, The Allegory of the Church. Romanesque Portals and Their Verse Inscriptions, Toronto, 1998, p. 129; JuAn Francisco Esteban Lorente, "Las inscripciones del tímpano de la Catedral de Jaca", Artigrama, 10 (1993), pp. 143-161; RoBert FaVreaU, "Les inscriptions du tympan de la Cathédrale de Jaca", Académie des Inscriptions et Belles-Letres, 1996, pp. 535-560; JuAN FrANCISCO EsteBAN LORENTE, "El tímpano de la catedral de Jaca (continuación)", en: Aragón en la Edad Media XIV-XV. Homenaje a la profesora Carmen Orcástegui Gros, Zaragoza, 1999, p. 462.

19 Calvin B. Kendall, "The Verse Inscriptions of the Tympanum of Jaca and the Pax Anagram”, Mediaevalia 19 (1996), p. 415.

${ }^{20}$ Una de las inscripciones de Jaca indica esta idea: HAC IN SCVLPTURA LECTOR SIC NOSCERE CVRA / P. PATER. A. GENITVS. DVPLEX EST SP(irutu)S ALMUS / HII TRES IVRE QVIDEM doMINVS SVUNT VNVS 
dencia dual de letras y significados puede encontrarse en textos teológicos de mediado el siglo $\mathrm{X}$ como el Comentario a la Epístola a los Efesios de Atto de Vercelli ${ }^{21}$. El organigrama interno varía según el tipo añadiéndose además con frecuencia las letras A y w para subrayar el principio apocalíptico del inicio y fin de todas las cosas. En resumen, el crismón sería una síntesis de buena parte del mensaje cristiano que con cierta estructura acróstica plantearía tres posibles combinaciones de letras, es decir, de lecturas: un anagrama/monograma de Cristo asociado al misterio de la Trinidad, principio y fin de todas las cosas.

Sería improcedente dado el carácter de estas breves reflexiones realizar un repaso a propósito de la lenta codificación de este símbolo desde época paleocristiana. Baste señalar que el crismón fue un recurso simbólico muy utilizado desde finales del siglo IV y en adelante, con san Isidoro como importante correa de transmisión y concentrando el interés de autores carolingios como Rabano Mauro o el arzobispo Hincmar de Reims entre otros ${ }^{22}$. La implantación y expansión de este iconograma desde fines del siglo XI y a lo largo de muy buena parte del XII en territorio pirenaico es un hecho sobre el que se ha trabajado considerablemente desde hace décadas. El más elaborado de estos crismones es sin lugar a dudas el de Jaca cuya compleja conformación en un marco circunvalado por inscripciones y figuras no admite parangón con ningún otro (fig. 6). Y sirve además para subrayar una de las características de este monograma, su habitual presencia en las puertas buscando una afirmación del dogma del filioque y apelando a la salvación del hombre al final de los días mediante el camino de Cristo. En el caso de Jaca, como en la mayor parte de las iglesias que lo tienen, preside la entrada occidental a la catedral. Recientemente se ha señalado que las complejas inscripciones podrían haber sido inspiradas por la obra De Trinitate del obispo de la sede gascona de Auch, san Orentius (fines del siglo IV y comienzos del V). El hecho de que este prelado de época visigoda asociara el crismón a la Trinidad y al término PAX, que su culto estuviera muy arraigado en el Suroeste de Francia y que un buen número de las iglesias pirenaicas a él dedicadas fueron ornamentadas con crismones lo convierten en referencia fundamental para entender la presencia y la etimología última de este símbolo ${ }^{23}$.

Otro aspecto de gran interés del crismón de Jaca en su integral concepción dentro del complejo tímpano, es el que atañe a su contexto topográfico, es decir, a su ubicación en el acceso principal de la catedral y frente al pórtico. En este sentido se ha subrayado su carácter de vehemente exhortación a la penitencia ${ }^{24}$. El ritual de penitencia pública, reservado a la autoridad episcopal, se llevaba a cabo ante las puertas de las catedrales entre el miércoles de ceniza y el Jueves Santo $^{25}$. La presencia de numerosas referencias visuales y escritas hace inequívoco este

ET IDEM ["En esta escultura, lector, procura entender lo siguiente: la P (rho) indica el Padre, A (alfa y omega) es el Hijo engendrado; la doble letra (X) representa al Espíritu Santo (que da la vida). Ellos tres sin duda son por derecho un único y el mismo Dios" [Trad.: J. F. Esteban] (JuAn Francisco Esteban Lorente, "Las inscripciones del tímpano de la Catedral de Jaca", p. 148; Robert Favreau, "Les inscriptions du tympan de la Cathédrale de Jaca", p. 551-553; CALVIN B. Kendall, "The Verse Inscriptions of the Tympanum of Jaca and the Pax Anagram", pp. 405-434.

21 Peter Scott Brown, "Portal, Sculpture, and Audience of the Romanesque Cathedral Sainte-Marie d'Oloron", Ph. D. Dissertation, Yale University, 2004, p. 223-224.

${ }^{22}$ Idem, pp. 225-226.

${ }^{23}$ Id., pp. 226 y ss. Hay que reseñar la importancia de Gascuña en el proceso de romanización religiosa del Noroeste peninsular y su estrecha comunidad de formas artísticas. Una síntesis de este asunto: MARCEL DuRLIAT, "La Gascogne dans l'art", en: Congrès Archéologique de France, $128^{e}$ Session 1970. Gascogne, París, 1970, pp. 9-18.

${ }^{24}$ En torno al marco penitencial en el que se inserta el tímpano de la catedral de Jaca en medio del pórtico ver: Serafín Moralejo Álvarez, "La sculpture romane de la cathédrale de Jaca. État des questions", Les Cahiers de SaintMichel-de-Cuxa, 10 (1979), pp. 93-97. Más ampliamente: Susan Havens Caldwell, "Penance, Baptism, Apocalypse: The Easter Context of Jaca Cathedral's West Tympanum", Art History 3 (1980), pp. 25-40.

25 Sobre este uso ver la lectura iconográfica del destruido tímpano septentrional de la catedral de Autun: Отто Karl Werckmeister, "The Lintel Fragment Representing Eve from Saint-Lazare, Autun”, Journal of the Warburg and Courtauld Institutes 35 (1972), pp. 1-30, espec. 15 y ss. 
Fig. 6. Tímpano de la catedral de Jaca (Foto: autor).

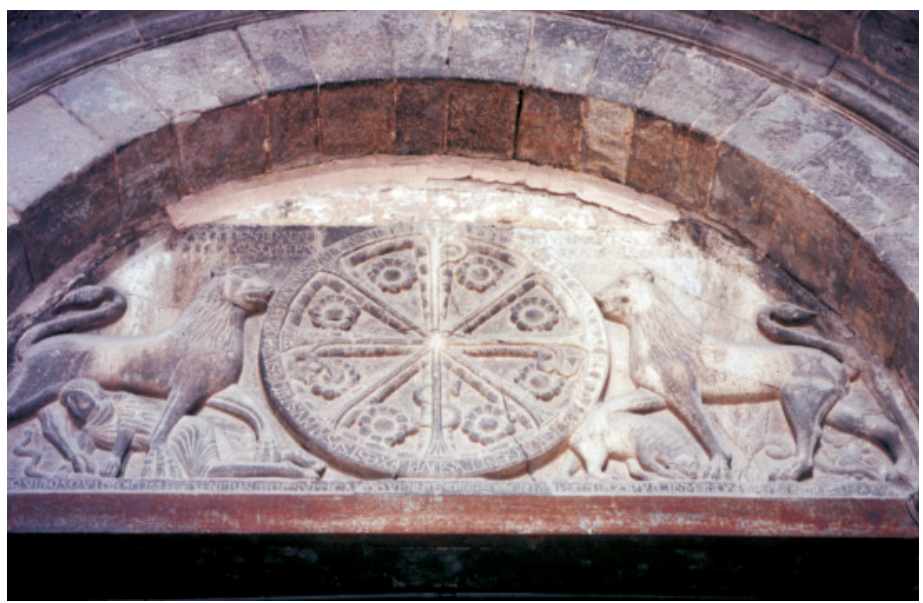

uso litúrgico que adquiriría el aludido sentido paulino de reconciliación (PAX) con el pecador arrepentido que accede al templo de $\operatorname{Dios}^{26}$.

En los crismones de Tierra de Campos no existe esta complejidad que acabamos de ver en Jaca. Fuera de la semejanza compositiva mediante seis radios, el crismón aparecido en San Zoilo es bastante diferente al de Frómista tanto en su factura como en su diseño. Mientras que aquél se resuelve mediante un trazo fino y anguloso, es decir, más simple, el de San Martín presenta un tratamiento más grueso y plástico que en este particular asunto lo hace más próximo al de $\mathrm{Jaca}^{27}$. Por otro lado, mientras el de Frómista prescinde de la $S$, el de Carrión tiene como singularidad que las letras alfa y omega, tradicionalmente a la derecha e izquierda, se encuentran invertidas ${ }^{28}$. Procedimiento que se constata ya en época tardoantigua y en territorio pirenaico ${ }^{29}$, los paralelos más próximos de esta disposición se encuentran en la puerta de acceso desde la iglesia a las dependencias palatinas de San Isidoro de León, en el interior del hastial occidental (ca. 1117-1124) ${ }^{30}$ (fig. 7), y en la fachada de Platerías de la Catedral de Santiago de Compostela (ca. 1103-1112) (fig. 8) rodeado, al igual que el de Jaca, de leones ${ }^{31}$. La explicación de tal inversión de caracteres se ha explicado a partir de la búsqueda de una mejor lectura del término PAX. Desplazando la $A$ al lado derecho el sentido de la lectura facilitaría la formación de esa palabra sin importunar la presencia simultánea del Alfa y la Omega ${ }^{32}$.

${ }^{26}$ Calvin B. Kendall, "The Verse Inscriptions of the Tympanum of Jaca and the Pax Anagram", pp. 412-413.

${ }^{27}$ La diferencia fundamental con Jaca se encuentra en el número de radios ya que mientras que el aragonés presenta ocho, el castellano sólo seis careciendo además de la $S$ en el radio vertical inferior.

${ }^{28}$ Calvin Kendall señala tres ejemplos de esta misma inversión en la iglesia pirenaica de Sainte-Engrâce, en la de Bosòt (Valle de Arán) o en la de San Pedro de la Rúa (Estella) (CAlvin B. Kendall, The Allegory of the Church, pp. 134-135).

${ }^{29}$ El sarcófago de san Léothalde, quizá del siglo V y conservado en la catedral de Auch, es un ejemplo a tener muy en cuenta dado el lugar en el que se conservó. Ver: Marcel Durliat, "La Gascogne dans l'art", p. 11.

${ }^{30}$ En torno a esta cronología ver: Therese Martin, Queen as King: Politics and Architectural Propaganda in Twelfth-Century Spain, Leiden, 2006, figs. 3 y 84. Las semejanzas del crismón de Frómista en la configuración plástica de radios y letras son bastante estrechas respecto al de San Isidoro.

${ }^{31}$ Es especialmente interesante la cristalización del crismón compostelano ya que en el tímpano derecho de Platerías dedicado a la Pasión, en el nimbo crucífero de Cristo aparecen las letras alfa y omega asociadas a la palabra PAX (CALvin B. Kendall, "The Verse Inscriptions of the Tympanum of Jaca and the Pax Anagram", pp. 420-423; The Allegory of the Church, pp. 136-137).

32 Calvin B. Kendall, The Allegory of the Church, p. 134; "The Verse Inscriptions of the Tympanum of Jaca and the Pax Anagram", pp. 420-423. 

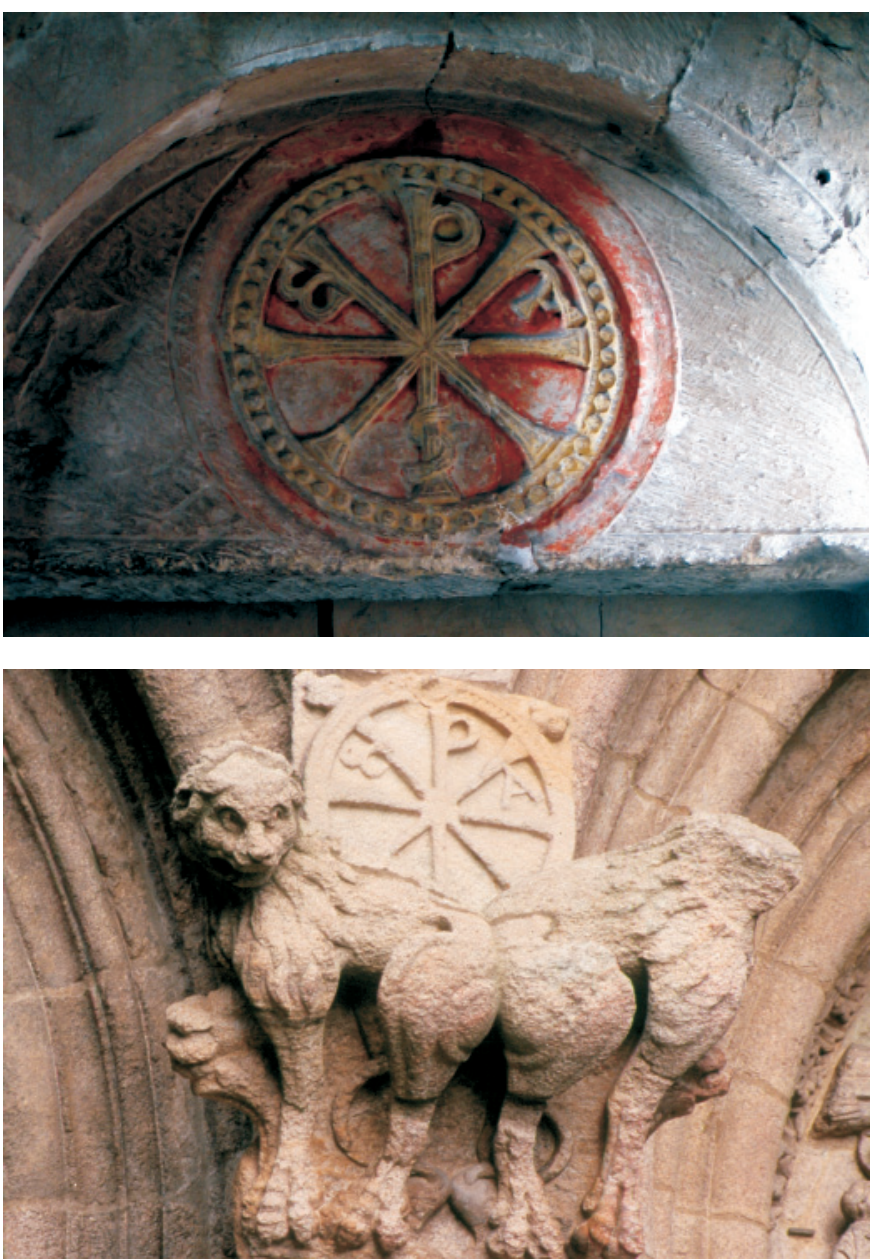

Fig. 7. Puerta a las dependencias palatinas. San Isidoro de León (Foto: autor).

Fig. 8. Fachada de Platerías.

Catedral de Santiago de Compostela (Foto: autor).

El contenido trinitario del crismón debe responder a un contexto de afirmación dogmática que se ha querido ubicar en el clima de reforma litúrgica que sacudió el reino de Aragón primero y posteriormente el resto de reinos del noroeste de la Península Ibérica ${ }^{33}$. En 1071 cesaba el uso del rito hispánico en territorio aragonés y, tras varias tentativas, finalmente en 1080 se asistía a su defunción oficial en Castilla, León y Galicia ${ }^{34}$. En los últimos años se ha propuesto que el crismón llevaba también consigo la evidencia del pacto realizado entre la monarquía aragonesa y el pontífice testimoniando además el compromiso de aquélla en pro de la conquista

${ }^{33}$ Sobre el contexto del crismón en el clima reformista en Aragón: Dulce Ocón Alonso, Tímpanos románicos españoles: reinos de Aragón y Navarra (Colección Tesis Doctorales, n. ${ }^{\circ}$ 76/87), Universidad Complutense de Madrid, 1985, tomo II, pp. 61 y ss.; "Problemática del crismón trinitario", Archivo Español de Arte, LVI (1983), pp. 251 y ss.; "El sello de Dios sobre la iglesia: tímpanos con crismón en Navarra y Aragón", en: El tímpano en la Iberia medieval: imágenes, estructuras y audiencias (R. SÁnchez AmeiJeiras / J. L. SenRa Gabriel y Galán, coord.), Santiago de Compostela, 2003, pp. 92 y ss.; Peter Scott Brown, "Portal, Sculpture, and Audience of the Romanesque Cathedral Sainte-Marie d'Oloron", pp. 215 y ss.

34 Teofilo F. Ruiz, "Burgos and the Council of 1080", Santiago, Saint-Denis and Saint-Peter: The Reception of the Roman Liturgy in Leon-Castille in 1080 (B. F. REILLY, ed.), New York, 1985, pp. 121-130. 
evangelizadora de las tierras sujetas al Islam ${ }^{35}$. El abandono de su representación en el siglo XIII sería un argumento para reforzar esos valores ${ }^{36}$. Asimismo el crismón podría llevar detrás una intencionalidad ecuménica romana encaminada a enfatizar la continuidad histórica y litúrgica con la primera Iglesia Romana en un territorio sumido en un aferrado particularismo ${ }^{37}$. Sabemos bien que en los territorios gobernados por Alfonso VI esta mutación ritual no se produjo de una manera fulminante sino más bien lenta y paulatina a lo que debió contribuir el aludido clima de confrontación iniciado tras la muerte del monarca en 1109. Es significativo cómo el crismón de San Zoilo encuentra un eco en el epitafio de la condesa Teresa de Carrión (ob. 1093), en el que existe un referencia clara y explícita a la trinidad de Dios ${ }^{38}$. Teresa, hay que recordarlo, fue la responsable de que lo que hasta 1076 era un próspero monasterio familiar pasara a formar parte de la orden de Cluny. Existen buenas razones para considerar que el inicio de la construcción del edificio románico se sitúe en las proximidades de su muerte. Una estructura románica como ésa debió incorporar de manera enfática un buen número de las preocupaciones religiosas y teológicas de los cluniacenses. Ya hemos visto un referente claro en la estructura occidental. Pero también es significativo el amplio y heterogéneo registro iconográfico de carácter netamente gregoriano, aplicado con intensidad en la iglesia de Frómista, con el que pudo estar dotada también la de San Zoilo. El convencimiento por parte de la orden de que se encontraba realizando su misión en un territorio atípico lo ponen de relieve numerosos testimonios documentales ${ }^{39}$. Frente a un carácter más público de los crismones de acceso a los templos catedralicios y parroquiales, aquí nos encontramos en una esfera más vinculada a la actividad de clausura. En este sentido el contexto de las procesiones litúrgicas y en relación con ellas el papel que adquiría el extremo occidental del templo con sus dos niveles de culto con el que se relaciona este criptograma trinitario no es una cuestión menor. Las escaleras por las que accedía la comitiva de monjes en un sentido ascensional desde un espacio terrestre a un espacio ligado a la Resurrección, con el cuño del dogma romano en su acceso, podían además asociarse fácilmente a la escalera mística del sueño de Jacob, pasaje bíblico muy comentado por la patrística y presente en la propia Regla de San Benito si bien de un modo estrictamente metafórico al referirse a la humildad en sus diferentes grados o peldaños de ascenso hasta Dios (capítulo VII) ${ }^{40}$. La referencia al ascenso y descenso de

35 Dulce OCón Alonso, "El sello de Dios sobre la iglesia: tímpanos con crismón en Navarra y Aragón”, pp. 94-101.

36 Peter Scott Brown, "Portal, Sculpture, and Audience of the Romanesque Cathedral Sainte-Marie d'Oloron", p. 218.

37 Idem, p. 216.

${ }^{38}$ Femina chara Deo iacet hoc tumulata sepulcro / quae comitissa fuit nomine Tarasia / haec mensis junii sub quinto transiit idus / omnis eam plangere debet homo / aecclesia pontem peregrinis optima tecta / fecit parca sibi largaque pauperibus / donet et regnum quod permanet omne per aevum / qui manet et trino regnat ubique Deus. Era MCXXXI ("Mujer amada de Dios yace enterrada en esta sepultura la condesa Teresa. Murió a los nueve días del mes de junio y por sus méritos la deben llorar todos. Edificó la iglesia, el puente y el hospedaje para los peregrinos. Siempre frugal para sí misma y generosa con los pobres. Dios que siendo trino reina por todas partes le conceda el reino que permanece para siempre. Murió en la Era de 1131"). Sobre el contexto de los sepulcros de Carrión: José Luis SenRA, "Mio Cid es de Bivar e nos de los condes de Carrión. Los Banu-Gómez de Carrión a la luz de sus epitafios”, pp. 240-243.

39 Marius Férotin, "Une lettre inédite de Saint Hugues abbé de Cluny a Bernard d'Agen, archevêque de Tolède (1087)", Bibliothèque de l'École des chartes, LXI (1900), pp. 339-345; "Complément de la Lettre de Saint Hugues, Abbé de Cluny à Bernard d'Agen, Archevêque de Tolède (1087)", Bibliothèque de l'École des chartes, LXIII (1902), pp. 684-688. A este respecto ver también los numerosos pasajes de la Historia Compostelana.

40 "Tuvo un sueño. Veía una escalera que, apoyándose en la tierra, tocaba con su cima en el cielo, y por la que subían y bajaban los ángeles de Yavé" (Gén. 28, 12). Sobre la escalera celeste en el arte medieval: WALTER CAHN, "Ascending and Descending from Heaven: Ladder Themes in Early Medieval Art", en: Santi e demoni nell'alto medioevo occidentale (secoli V-XI), Spoleto, 1989, pp. 697-724; ChristiAn Heck, L'échelle céleste dans l'art du Moyen Âge. Une image de la quête du ciel, Paris, 1997, pp. 43 y ss. Una síntesis sobre la significación de la escalera como metáfora: Anabel López Gómez, "Échelle", en: Dictionnaire critique d'Iconographie Occidentale (X. BARral i Altet, dir.), 
los "ángeles de Yavé" del pasaje bíblico podría encontrar también fácil acomodo en los repetidos paralelos establecidos entre los ángeles y los monjes de Cluny ${ }^{41}$. Para este aspecto vuelve a ser muy sugerente la iglesia del monasterio de Saint-Pé-de-Bigorre (Hautes-Pyrénées), institución muy próxima a los presupuestos litúrgicos cluniacenses, con un concepto de fachada occidental no muy alejada de las de Frómista, Dueñas y San Zoilo y situada en una cronología semejante, los comienzos del siglo XII ${ }^{42}$. En la torre de ángulo que aún conserva, la noroeste, se mantiene también su puerta de acceso en la que ha desaparecido el tímpano pero no por completo la inscripción que lo circunvalaba. El contenido, de carácter apotropaico y penitencial, hace referencia, si bien de modo un tanto genérico, a la VIA CAELI ${ }^{43}$. Por otro lado era una puerta de acceso a la tribuna pero también a una capilla alta ubicada en la parte alta de la torre, probablemente bajo el patronazgo de san Miguel y solidaria por lo tanto con el concepto apocalíptico y apotropaico del conjunto de la fachada occidental ${ }^{44}$.

En definitiva, el crismón aparecido en el antiguo priorato cluniacense de San Zoilo manifiesta la amplia expansión de este recurso iconográfico, extraordinariamente asentado en Gascuña y Aragón, hacia el noroeste peninsular. Desde su estricto valor como fuente documental para profundizar en el asentamiento, cristalización y desarrollo del Románico maduro en los territorios castellano-leoneses, podría verse como un cabalístico copyright pirenaico que subrayaría el gran impulso emanado de aquella fructífera área territorial en las décadas fronteras al año 1100.

Fecha de recepción: 22-I-2007

Fecha de aceptación: 4-VI-2007

Rennes, 2003, pp. 285-288. Sobre una posible aplicación arquitectónica de la humildad benedictina en las escaleras de acceso a las cubiertas de la catedral de Orense: Rocío SÁnchez AmEIJEIRAS, "Algunos aspectos de la cultura visual en la Galicia de Fernando II y Alfonso IX”, en: El Arte Románico en Galicia y Portugal, La Coruña, 2001, pp. 162-165. La metáfora de la ascensión como alegoría de la vida espiritual aparece también en otra literatura benedictina extraordinariamente difundida como son los Moralia in Job de san Gregorio, esta vez fundamentándose en la palmera del Cantar de los Cantares (Christian Heck, L'échelle céleste dans l'art du Moyen Âge, pp. 158-159).

${ }^{41}$ Aun siendo un recurso de la retórica cristiana, son varios los testimonios que pueden traerse: en la relación epistolar de Fulberto de Chartres con Odilón de Cluny, aquél equiparaba en varios pasajes al abad con los ángeles (arcangelus monachorum) (JACQues Hourlier, Saint Odilon Abbé de Cluny, Louvain, 1964, p. 130) y el semejante parangón usaba en los mismos años Raúl Glaber al referirse al coro de monjes cluniacenses (Rodulfi Glabri, Historiarum libri quinque (J. France, ed.), Oxford, 1989, p. 236). Ver también: Sophie CASSAGNES-Brouquet, "Cluny et les anges. Les créatures célestes dan la spiritualité et l'art clunisien", Les Cahiers de Saint-Michel de Cuixà XXVIII (1997), pp. 21-27.

42 Sobre esta iglesia ver nota 2.

${ }^{43}$ EST DOMus HIC DomiNI VIA CAELI SPES PEREGRINI HAEC DATA PORTA PETRO VADE MALIGNE RETRO (“Aquí está la casa del Señor, el camino del Cielo, la esperanza del peregrino. Esta puerta está dedicada a Pedro. Retroceda el maligno") (CALvin B. Kendall, The Allegory of the Church, pp. 107-108, 274).

${ }^{44} \mathrm{La}$ iconografía de la portada occidental de San Zoilo presenta esta misma dirección con capiteles que van desde la ascensión del alma hasta la debilidad de la Fe, muy coherentes con el espacio funerario contiguo. Sobre este asunto: José Luis Senra, "Mio Cid es de Bivar e nos de los condes de Carrión. Los Banu-Gómez de Carrión a la luz de sus epitafios", pp. 236-237. Sobre las capillas altas dedicadas a Miguel: JEAn VALLERY-Radot, "Note sur les chapelles hautes dédiées a Saint Michel”, Bulletin Monumental, 88 (1929), pp. 454-478. Recientemente sobre este asunto en ámbito hispano: FrANCESCA ESPAÑOL, "Culte et iconographie de l'architecture dédiés a Saint-Michel en Catalogne", Les Cahiers de Saint-Michel de Cuixà, XVIII (1997), pp. 175-186; PATRICK Henriet, "Protector et defensor omnium. Le culte de Saint-Michel en la Péninsule Ibérique (Haut Moyen Âge)", en: Culto e santuari di san Michele nell'Europa medievale. Culte et sanctuaires de saint Michel dans l'Europe médiévale (Atti del Congresso Internazionale di studi, Bari - Monte Sant'Angelo, 5-8 aprile 2006) (P. Bouet, G. Otranto, A. VaucheZ, ed.), Bari, 2007, pp. 113-131. 